\title{
The Effectiveness of "Xuexitong" in College English Teaching
}

\author{
Fen Zhang ${ }^{1}$ and Min She ${ }^{1, *}$
}

\author{
${ }^{1}$ Chengdu Medical College, Chengdu, Sichuan 610500, China \\ *Corresponding author. Email: shirleycs@163.com
}

\begin{abstract}
In order to know whether the college English teaching with the application of "Xuexitong" can improve students' autonomous learning ability, English writing ability and the English comprehensive ability or not, comparative experiment of 8 classes of nursing students of grade 2020 in our college was conducted. The experimental group adopted college English teaching with the application of "Xuexitong" while the control group adopted the traditional college English teaching. The results of the experiment show that reasonable application of "Xuexitong" into college English teaching can effectively improve learners' autonomous learning ability and learning initiative. The enhancement of autonomous learning ability and learning initiative correspondingly promotes the improvement of learners' English writing ability and English comprehensive ability to a certain extent, which brings more effectiveness to college English teaching. Keywords: Xuexitong, college English writing, autonomous learning ability, effectiveness
\end{abstract}

\section{INTRODUCTION}

In the late 20th century, the cultivation of autonomous learning ability has been widely concerned by experts and scholars at home and abroad. Holec (1981) pointed out that autonomy is "the ability to be responsible for one's own learning", and autonomous learning is "the ability to manage one's own learning", which is mainly manifested in: setting learning objectives, determining learning content and process, selecting methods and techniques, monitoring acquisition process and evaluating learning results. [1] According to B.J. Zimmerman, when students actively participate in motivation, behavior and metacognition, their learning is autonomous. [2] Oxford believes that there are three main types of metacognitive strategies adopted by language learners: planning strategies, monitoring strategies, and adjustment strategies. Learners evaluate their learning effects and adjust learning strategies in time. They believe that metacognitive strategies will restrict and regulate learners' choice of other learning strategies, especially in autonomous learning. [3] Piaget put forward the theory of cognitive structure, which advocates that cognition is the structural action and activity formed in the process of the subject changing the object, and emphasizes the process that the new knowledge is connected with the knowledge structure formed before. [4] In other words, learning can only happen if learners play an active role in the cognitive process of their interaction. Bruner inherited and developed Piaget's genetic epistemology and put forward discovery learning theory, emphasizing the important role of cognitive process, cognitive structure and learners' independent thinking in learning. [5] Both Bruner and Piaget emphasize the subjectivity and importance of cognitive structure and learners' self-regulation.

Previous studies on autonomous learning, cognitive strategies and metacognitive strategies show that learners' autonomous learning ability can be improved by cultivating their cognitive strategies and metacognitive strategies. In the past, the research on autonomous learning strategy mainly focused on the strategy itself, but little research was conducted on the ability of autonomous learning from the perspective of learning motivation. Nowadays, advanced electronic information technology has been integrated into college English teaching reform. With the improvement of mobile phone intelligence in recent years, more and more mobile applications related to English learning have been developed. These mobile applications are easy to use and less restricted by time and place, covering five aspects of listening, speaking, reading, writing and translation, which bring about great convenience to English learning for learners. Mobile learning based on mobile applications should become a powerful supplement to college English classroom teaching. Mobile learning based on mobile apps should become a powerful supplement to college English classroom teaching. This kind of autonomous learning mode is conducive to English learners to effectively use the fragmented time to improve their English level, such as increasing vocabulary, improving listening and speaking, reading and writing skills. Therefore, English teachers should pay enough attention to this. At present, college English teaching does not make full use of these mobile learning resources. Clark Quinn, a foreign scholar, believes that mobile learning is the product of the combination of mobile computer and digital learning. It includes learning resources, powerful search ability and rich interaction. Mobile applications developed under the guidance of 
mobile learning theory provide a powerful application platform for college English teaching reform. English teachers should pay enough attention to the application of mobile applications in college English teaching. To comply with the trend of the times, the Academic Affairs Office of our college has introduced the mobile application "Xuexitong", and encourages teachers to actively create courses in the platform, so as to help students improve their learning effect. "Xuexitong" is a platform for course learning, knowledge dissemination and management sharing based on micro service. It makes use of the massive resources of books, periodicals, newspapers, videos and original works accumulated by Beijing Century superstar Information Technology Development Co., Ltd for more than 20 years. It integrates knowledge management, course learning, thematic creation and office application, providing readers with a one-stop learning and working environment. "Xuexitong" can easily realize the interaction between teachers and students in English classroom, greatly improve students' classroom participation, effectively change "Teacher-centered" teaching into "student-centered" teaching, and effectively improve students' classroom concentration. After class, teachers can also use "Xuexitong" to arrange learning tasks, which is convenient for teachers to check and urge students to carry out autonomous learning. Language learners' motivation, subjective attitude and disposition have the greatest influence on language learning. In the process of learning, learners can promote language learning by enhancing their motivation and interest in language learning and changing their subjective attitudes. Therefore, it is necessary to study whether "Xuexitong" can improve students' autonomous learning ability and their comprehensive English ability. At present, there are few researches on the application of mobile applications in college English teaching. Duan ting and Wang Shuqin (2015) have studied the autonomous learning mode of college English based on mobile app.[6] Dou Juhua and Wen Shan (2015) have explored the flipped classroom teaching of college English based on app. [7] These studies focus on mobile applications as a way to learn English. In this research, "Xuexitong" is fully applied to classroom teaching and classroom management, and the influence of English teaching based on "Xuexitong" on learners" autonomous learning ability and learning effect is studied. From the perspective of stimulating students' English learning motivation, the effectiveness of applying "Xuexitong" to college English teaching is studied, and how to scientifically use mobile applications to improve English learning effect and promote college English teaching under the new technology conditions is explored.

\section{RESEARCH METHODS}

The subjects of this study are undergraduates of grade 2020 majoring in nursing from 8 teaching classes in our college. Comparative patterns of teaching are adopted to carry out the research. In the autumn semester of 2020, the experimental group adopted "Xuexitong" more frequently in the teaching process, while the control group participated in the traditional teaching and seldom apply "Xuexitong" to the their teaching process. The pretest was conducted shortly after the students' entering the college with English test paper for college entrance examination, and the pretest data were obtained according to the students' scores, so as to know the students' English learning situation before the experiment.

In December 2020, after the end of the semester, the students in the experimental group and the control group were tested with the final-term examination papers and a set of questionnaires involving cognitive strategies and metacognitive strategies. The data of the posttest were collected to know the students' English learning status, the change of autonomous learning ability, the change of English writing ability and the change of English comprehensive ability after the experiment. The questionnaire used in this study is mainly based on Oxford's (1990) metacognitive strategy questionnaire, combined with the metacognitive strategy classification theory of o'mally and Chamot (2001), and the actual situation of students in our school. The questionnaire contains 30 questions. The 5-level scoring system of Likert scale was used in the questionnaire. The numbers 1-5 represent "completely inconsistent, not quite consistent, uncertain, relatively consistent and completely consistent". Through SPSS13.0, the test results of the experimental group and the control group before and after the experiment were compared, and the differences of English writing ability and comprehensive English ability between the two groups before and after the experiment were analyzed; through the comparison of the questionnaire survey results of the two groups after the experiment, the differences of their autonomous learning ability were analyzed.

\section{RESEARCH CONTENT}

In the autumn semester of 2020, the students in the experimental group participated in a semester of English classroom teaching with the application of "Xuexitong". "Xuexitong" is mainly used in the following three teaching links: (1) "Xuexitong" is used in each unit when warm-up activities are conducted, and the students will express their personal views for mutual sharing and learning according to the given discussion topics. This kind of "brainstorming" of divergent thinking effectively associates students' original knowledge schema and new knowledge points, which is very helpful for students to expand vocabulary. Teachers can also effectively improve students' enthusiasm to participate in the discussions through praise and bonus points, which is conducive to prolonging students' classroom concentration. (2) In the autumn semester, two units are arranged to be learned through group discussion. Each group shares the results of the given discussion topic via "Xuexitong", and learns from each other and evaluates the discussion results of other groups, so as to help everyone better understand the 
main idea of the article. The formative evaluation of this "peer assessment" mode can help students find out their own diseases and actively seek solutions through peer evaluation and self-evaluation, so as to realize self-improvement. (3) Two classroom activities are arranged in the autumn semester to revise students' compositions via "Xuexitong". After students hand in their composition, the teacher selects 3-5 compositions, and provides feedback information by underlining the sentence with errors. After taking photos, by projecting the chosen composition via "Xuexitong", the students can appreciate the beautiful sentences and analyze the problematic sentences according to the teacher's feedback, and finally put forward their own modification suggestions. This learning process can help students improve their language awareness and sentence structure ability through knowledge feedback, so as to improve their language output ability. After class, the teacher investigates the students in the experimental group through "Xuexitong" to facilitate timely communication and grasp the students' learning situation; the teacher posts assignments via "Xuexitong" to facilitate inspection and urge students to review in time.

\section{RESULTS AND ANALYSES}

After entering the college, before the experiment, the experimental group and the control group were tested with the same test paper, which is college entrance examination English paper, therefore, the reliability and validity of the test paper can be guaranteed. The test paper includes listening, reading and writing. The average score of the experimental group is 71.87 , and the standard deviation is 7.528 ; the average score of the control group is 72.19 , and the standard deviation was 7.766. Independent sample t-test results shows that there is no significant difference between the experimental group and the control group $(\mathrm{P}>0.05)$. The results show there is no significant difference in the overall English performance (English comprehensive ability) between the experimental group and the control group before the experiment.

As to the post-test, which is the college final-term test, the average score of the experimental group is 82.43 , and the standard deviation is 6.627 ; the score of the control group is 77.59, and the standard deviation is 8.886 . Independent sample t-test results show there is significant difference between the experimental group and the control group $(\mathrm{P}<$ $0.05)$. The results show that there is a significant difference in the overall English performance (English comprehensive ability) between the control group and the experimental group, which proves that the college English teaching with the application of "Xuexitong" can help students improve their English learning performance more effectively than the traditional college English teaching.

Before the experiment, the average composition scores of the experimental group and the control group were from five teachers of the research group. The average score of the experimental group is 8.69 with the total score of 15 , and the standard deviation is 2.009 ; the score of the control group was 8.73 and the standard deviation is 2.007 . Independent sample t-test results show there is no significant difference in students' writing ability between the experimental group and the control group $(\mathrm{P}>0.05)$.

After the experiment, the average composition score of the experimental group is 10.48 with the total score of 15 , and the standard deviation is 1.517 ; the score of the control group is 9.01 and the standard deviation is 1.866. The results of independent sample t-test results show there is a statistically significant difference in writing performance after the experiment between the experimental group and the control group in the post-test $(\mathrm{P}<0.05)$, which proves that the application of "Xuexitong" can effectively improve the students' English writing ability as it allows the whole class to appreciate the excellent compositions of the class, correct the compositions with errors, and guide the writing methods.

The average score of autonomous learning ability in the experimental group is 112.55 , the standard deviation is 14.279 ; the score of the control group is 106.02, the standard deviation is 14.587 . The results of independent sample t-test results show there is significant difference in autonomous learning ability between the experimental group and the control group $(\mathrm{P}<0.05)$, which proves that the application of "Xuexitong" in college English teaching can effectively improve students' autonomous learning ability.

The average score of the pre-test in the control group is 72.19 , and the standard deviation is 7.766 ; the post-test score of the control group is 77.59, and the standard deviation is 8.886 . The results of paired sample t-test show there are significant differences between the experimental group and the control group in pre-test and post-test $(\mathrm{P}<0.05)$, which indicate college English teaching can improve students' English performance to a certain extent. The average score of the pre-test of the experimental group is 71.87 , and the standard deviation is 7.528 ; the post-test score of the experimental group is 82.43 , and the standard deviation is 6.627. The results of paired sample t-test show there are significant differences between the experimental group and the control group in pre-test and post-test $(\mathrm{P}<$ $0.05)$. The average score of the experimental group increases by 10.56, while that of the control group increases by 5.4. The results show that there is a statistically significant difference between the pre-test scores and the post-test scores of the experimental group. Compared with the traditional college English teaching, college English teaching with the application of "Xuexitong" can significantly help students improve their English learning.

\section{CONCLUSION}

To sum up, the research results show that college English teaching with the application of "Xuexitong" can improve learners' autonomous learning ability, English writing ability, and English comprehensive ability. "Xuexitong" can conveniently help teachers use questionnaire to know 
students' learning status, so that they can timely adjust teaching schedule and teaching arrangement, and promote effective communication between teachers and students, so as to promote college English teaching. "Xuexitong" provides students with convenient learning conditions and rich learning resources, and learners can realize English self-test at any time. The "notice" function of "Xuexitong" is convenient for teachers to supervise students and help them form good learning habits, including making learning plans, detecting learning situation and monitoring their own learning, and constantly adjusting learning plans and learning methods, etc. Students' learning initiative is correspondingly enhanced. The enhancement of autonomous learning ability and learning initiative promotes the improvement of English language comprehensive ability. The results of this study will play a practical role in the cultivation of college Students' autonomous learning ability.

The results of this experiment are persuasive, but due to the limited number of experimental samples, the research results have certain limitations. With the development and utilization of more functions of "Xuexitong", the flexible and diversified English teaching methods can help students improve their interest in English learning and learn the language more conveniently.

\section{ACKNOWLEDGMENT}

Teaching reform research project of Chengdu Medical College in 2020: Research on the Effectiveness of Mobile Application "Xuexitong" in College English Teaching (No: JG202020).
Sichuan Foreign Language and Literature Research Center "The Influence of Autonomous English Learning Based on Language Lab and Mobile Applications on Learners' Metacognitive Strategy Level" (No: SCWYH20-09)

\section{REFERENCES}

[1] Holec H. Autonomy and Foreign Language Learning [M]. Oxford: Pergamon, 1981:23-25.

[2] Zimmerman B.J. Social cognitive view of self-regulated academic learning [J]. Journal of Educational Psychology. 1989 (23): 329-339.

[3] Oxford R.L. Language Learning Strategies: What Every Teacher Should Know[M].

[4] Piaget J. Genetic Epistemology [M]. New York: Columbia University Press, 1970.

[5] Bruner J. Studies in Cognitive Growth [M]. New York: Wiley,1966.

[6] Duan Ting, Wang Shuqin. A Preliminary Study on College English Autonomous Learning Mode Based on Mobile App [J]. Changchun Education Journal of College of physical education, 2015 (12).(In Chinese)

[7] Li Hong. Analysis of the Practice and Application of Mobile App in English Audio Visual Oral Course [J]. Foreign language teaching, 2016 (23). (In Chinese) 